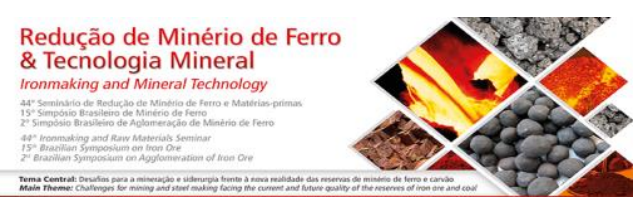

\title{
INFLUÊNCIA DA QUALIDADE DAS MATÉRIAS-PRIMAS NO ESCOAMENTO GASOSO NA ZONA GRANULAR DO ALTO-FORNO*
}

\section{Resumo}

Brenda Marise Oliveira Custódio Pereira ${ }^{1}$ Cláudio Musso Velloso² Luiz Fernando Andrade de Castro ${ }^{3}$ Ronaldo Santos Sampaio 4

Este trabalho apresenta uma análise fluidodinâmica de um leito granulado, utilizando-se partículas sólidas de diferentes característica em um leito de área de secção transversal circular. Os materiais utilizados foram aqueles comumente utilizados em um alto-forno a carvão vegetal. Os dados experimentais foram obtidos em um leito fluidizado fixo, de escala piloto, medindo $1,20 \times 1,00 \mathrm{~m}$. A fluidodinâmica foi estabelecida pelas medidas da perda de pressão no leito e vazões de ar crescentes. Os valores de velocidade de fluidização foram obtidos a partir dos gráficos de perda de pressão $\mathrm{x}$ velocidade do ar.

Palavras-chave: Permeabilidade; Equação de ergun; Escoamento gasoso; Leito granulado.

\section{INFLUENCE OF RAW MATERIALS IN GAS FLOW OF GRANULAR ZONE IN BLAST FURNACE}

\section{Abstract}

This paper presents an analysis of a fluid granular bed, using solid particles of different characteristics on a bed of circular cross section area. The materials used were those commonly used in a blast furnace charcoal. The experimental data were obtained in a fixed fluidized bed pilot scale, measuring $1.20 \times 1.00 \mathrm{~m}$. The fluid dynamics was established by measurements of the pressure drop in the bed and increasing air flow. The values of fluidization velocity are obtained from the graphs of loss of pressure $x$ velocity of the air.

Keywords: Permeability; Ergun equation; Gas flow; Granular bed.

1 Engenheira Química, Mestre em Engenharia Metalúrgica, Engenharia de Processos na Vallourec Tubos do Brasil S.A., Brasil.

2 Engenheiro Metalurgista, Mestre em Engenharia Metalúrgica, Gerente na Vallourec Tubos do Brasil S.A, Brasil.

3 Professor Associado, Departamento de Engenharia Metalúrgica e de Materiais, UFMG, MG, Brasil.

4 Engenheiro Metalurgista, M.Sc., Ph.D, Diretor RSConsultants Ltda, Brasil.

5 Estatística, Mestre em Estatística, Doutoranda em Engenharia Metalúrgica, UFMG, Coordenadora Técnica na Vallourec Tubos do Brasil S.A., Brasil.

* Contribuição técnica ao 44 Seminário de Redução de Minério de Ferro e Matérias-primas, 15ำ Simpósio Brasileiro de Minério de Ferro e $2^{\circ}$ Simpósio Brasileiro de Aglomeração de Minério de Ferro, 15 a 18 de setembro de 2014, Belo Horizonte, MG, Brasil. 
Redução de Minério de Ferro

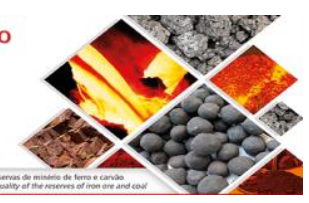

\section{INTRODUÇÃO}

A produção, o consumo específico de carvão vegetal e outras características importantes do alto-forno dependem dos dados técnicos de escoamento, entre os quais a perda de pressão na carga "seca". Na zona seca do alto-forno, as características da carga que afetam a permeabilidade do gás são determinadas através de ensaios chamados de ensaio de permeabilidade de leitos granulados. Os leitos granulados são formados por sólidos granulados irregulares de diferentes formatos e diâmetros ou também por aglomerados de partículas finas. As características dos leitos que afetam a permeabilidade são a fração de vazios, a esfericidade e o tamanho médio das partículas que compõem o leito. Além das características do gás injetado, são essas as características do leito granulado previstas na Equação de Ergun, que é a equação matemática utilizada para prever a queda de pressão em um leito de partículas.

Este estudo apresenta e analisa os resultados dos ensaios de permeabilidade aplicados a algumas matérias-primas normalmente utilizadas no processo de fabricação do ferro gusa: carvão vegetal, minério granulado e pelota. Com estes ensaios é possível obter as constantes geométricas características do granulado ( $k_{1}$ e $\left.k_{2}\right)$, sem que qualquer hipótese seja feita. Paralelamente, para estes mesmos materiais, foram feitas análises baseadas em padrões normativos para a medição da fração de vazios, esfericidade e tamanho médio, para que então fosse efetuado o cálculo dessas constantes geométricas do leito granulado. Por fim os resultados foram comparados aos correspondentes valores obtidos em equações empíricas e outros resultados retirados da literatura, para que se verifique se os valores observados confirmam as previsões do comportamento que se obtém teoricamente.

Ergun propôs que a perda de carga total em um leito poroso é constituído de dois termos: um representando a perda de carga laminar (do tipo Kozeny) e outro correspondente a perda de carga devido a turbulência (do tipo Burke-Plummer), ou seja:

$$
\frac{\Delta P}{H \cdot V_{0}}=150 \cdot \frac{(1-\varepsilon)^{2}}{\varepsilon^{3}} \cdot \frac{1}{d_{p}^{2}} \cdot \mu_{g}+1,75 \cdot \frac{(1-\varepsilon)}{\varepsilon^{3}} \cdot \frac{1}{d_{p}} \cdot \rho_{g} \cdot V_{0}
$$

$\mathrm{Na}$ equação (1), conhecida como Equação de Ergun, o primeiro termo à direita da equação representa a perda de carga devido aos efeitos viscosos (atrito interno no gás e na superfície dos grãos), e o segundo termo representa a perda de carga devido ao turbilhonamento do gás ao passar pelos grãos constituídos pelo leito poroso. Enquanto o escoamento em torno da partícula é laminar o gás somente perde energia (o que corresponde a uma perda de carga) devido ao atrito na superfície da partícula e entre as camadas de fluido. À medida que a velocidade do gás vai aumentando (aumento no número de Reynolds) começam a formar pequenos redemoinhos na parte superior da partícula, que vão aumentando com o número de Reynolds. Este turbilhonamento ocasiona uma perda de energia pelo fluido e conseqüentemente uma perda de carga, representada pelo segundo termo da Equação de Ergun.

* Contribuição técnica ao 44 Seminário de Redução de Minério de Ferro e Matérias-primas, 15ำ Simpósio Brasileiro de Minério de Ferro e $2^{\circ}$ Simpósio Brasileiro de Aglomeração de Minério de Ferro, 15 a 18 de setembro de 2014, Belo Horizonte, MG, Brasil. 


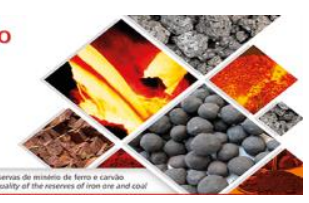

Levando em conta os efeitos da não esfericidade das partículas e da distribuição de tamanho destas partículas, como acontece com as matérias primas utilizadas no altoforno, a equação de Ergun passa a ter a seguinte forma:

$$
\frac{\Delta P}{H . V_{0}}=k_{1} \cdot \mu_{g}+k_{2} \cdot \rho_{g} V_{0}
$$

Onde:

$$
k_{1}=150 \cdot \frac{(1-\varepsilon)^{2}}{\varepsilon^{3}} \cdot \frac{1}{\left(\Phi . d_{p}\right)^{2}}
$$

$\mathrm{k}_{1}=$ coeficiente de resistência viscosa, $\left(\mathrm{m}^{-2}\right)$;

$$
k_{2}=1,75 \cdot \frac{(1-\varepsilon)}{\varepsilon^{3}} \cdot \frac{1}{\left(\Phi . d_{p}\right)}
$$

$\mathrm{k}_{2}=$ coeficiente de resistência inercial, $\left(\mathrm{m}^{-1}\right)$.

Para um leito de características geométricas definidas, os valores de $k_{1}$ e $k_{2}$ serão constantes e denominados, portanto, de constantes geométricas do leito granulado.

O início de fluidização ocorre quando a queda de pressão no leito é igualada ao peso do leito. Baseando-se neste fato, pode-se calcular a velocidade de fluidização das partículas, isto é, a velocidade na qual ocorre o início de fluidização. A partir das equações já apresentadas anteriormente é possível obter a velocidade superficial do gás que dará início a fluidização, $V_{\mathrm{f}}$ :

$$
V_{f}=\frac{-k_{1} \cdot \mu_{g} \pm \sqrt{\left(k_{1} \cdot \mu_{g}\right)^{2}+4 \cdot k_{2} \cdot \rho_{\text {leito }} \cdot \rho_{g}}}{2 \cdot k_{2} \cdot \rho_{g}}
$$

Observa-se que a velocidade de fluidização $V_{f}$ é função somente das características do leito ( $k_{1}, k_{2}$ e pleito) e do fluido $\left(\rho_{g}\right.$ e $\left.\mu_{g}\right)$.

\section{MATERIAIS E MÉTODOS}

\subsection{Ensaios para a Determinação da Esfericidade, Fração de Vazios e Tamanho Médio}

A Fração de Vazios foi obtida através da Medição da Densidade Relativa Aparente, utilizando a norma "NBR 9165: Carvão vegetal - Determinação da densidade relativa aparente, relativa verdadeira e porosidade". O procedimento contempla a imersão da amostra previamente quarteada, peneirada e seca em um recipiente cilíndrico preenchido com água.

Para determinação da esfericidade das partículas, foram coletadas aleatoriamente 200 partículas de cada material seco a $105^{\circ} \mathrm{C}$ até massa constante, de forma proporcional a análise granulométrica e tomadas a maior dimensão e a menor dimensão em cada

* Contribuição técnica ao 44 Seminário de Redução de Minério de Ferro e Matérias-primas, 15ำ Simpósio Brasileiro de Minério de Ferro e $2^{\circ}$ Simpósio Brasileiro de Aglomeração de Minério de Ferro, 15 a 18 de setembro de 2014, Belo Horizonte, MG, Brasil. 


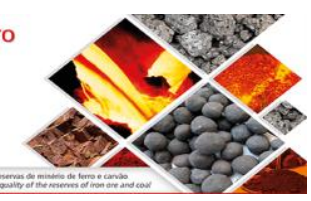

partícula analisadas, com o auxílio de um paquímetro digital, conforme NBR7809 Determinação do Índice de forma pelo método do paquímetro.

O tamanho médio da partícula é definido em termos de aberturas das peneiras onde as partículas são tratadas. Dessa forma, pode-se também considerar situações onde 0 tamanho das partículas não seja uniforme. Nesse caso, define-se um tamanho médio a partir da análise granulométrica.

\subsection{Ensaios de Permeabilidade}

O esquema do dispositivo empregado para os testes pode ser visto na Figura 1. O método empregado pode assim ser resumido: (1) o material peneirado na faixa granulométrica desejada é colocado sobre a tela de $6 \mathrm{~mm}$, no interior do dispositivo de medição; (2) a altura do leito granulado, em todas as medições é mantida igual a $1 \mathrm{~m}$, sem a compactação do material; (3) com o auxilio do ventilador dotado de inversor de freqüência, passou-se um volume de ar crescente através do leito granulado; (4) são tomadas as medições de temperatura e pressão do ar insuflado; (5) são medidas, para cada leito ensaiado, as quedas de pressão $\Delta \mathrm{P}$ em 4 medidores posicionados radialmente no tubo suporte do leito granulado; (6) as vazões foram determinadas por uma sonda de medição posicionada entre o ventilador e o tubo suporte do leito granulado. Para todas as medições de pressão utilizou-se manômetro tubo em "U".

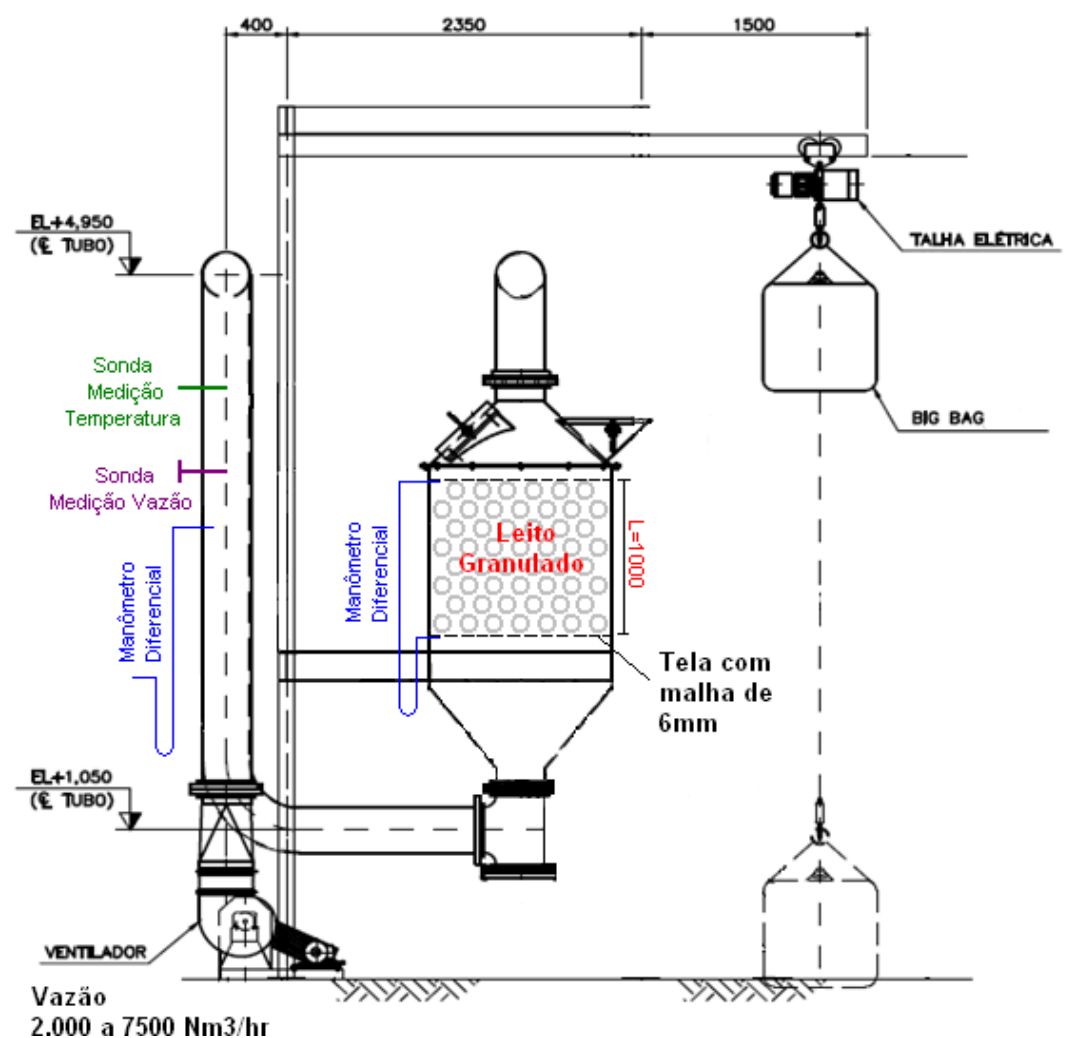

Figura 1: Esquema do aparelho de medição de $\Delta \mathrm{P}$ utilizado

* Contribuição técnica ao 44 Seminário de Redução de Minério de Ferro e Matérias-primas, 15은 Simpósio Brasileiro de Minério de Ferro e $2^{\circ}$ Simpósio Brasileiro de Aglomeração de Minério de Ferro, 15 a 18 de setembro de 2014, Belo Horizonte, MG, Brasil. 


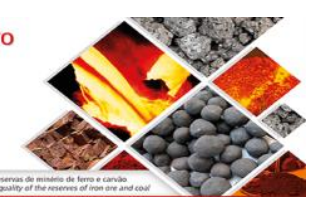

$\mathrm{O}$ medidor de $\Delta \mathrm{P}$ possibilita realizar medições da queda de pressão em leitos granulados constituídos não só de combustível como também de minérios de ferro e fundentes quando este é submetido a uma vazão conhecida de ar.

A Sonda de medição de vazão empregada opera sentindo uma pressão de impacto gerada pelo escoamento através de múltiplas portas sensoriais ligadas a uma câmara à montante e outra à jusante resultando em um diferencial de pressão, sendo o número de portas proporcional ao diâmetro da tubulação.

Assim, foram realizadas as medições de $\Delta P$ e Vazão nos diferentes leitos granulados montados experimentalmente e detalhados na Tabela 1 abaixo:

Tabela 1: Descrição dos experimentos avaliados

\begin{tabular}{cc}
\hline Material & Faixa Granulométrica \\
\hline Minério Granulado NPO & $6-30 \mathrm{~mm}$ \\
\hline Minério Granulado HTT & $6-16 \mathrm{~mm}$ \\
\hline Pelota A - 10 Ensaio & $8-18 \mathrm{~mm}$ \\
\hline Pelota A - 20 Ensaio & $8-18 \mathrm{~mm}$ \\
\hline Pelota A - 30 Ensaio & $8-18 \mathrm{~mm}$ \\
\hline Pelota B & $8-18 \mathrm{~mm}$ \\
\hline Pelota B - peneirada em 6,35mm & $8-18 \mathrm{~mm}$ \\
\hline Carvão Grosso & $32-125 \mathrm{~mm}$ \\
\hline Carvão Médio & $10-32 \mathrm{~mm}$ \\
\hline Carvão & $10-125 \mathrm{~mm}$ \\
\hline Carvão - Distribuição em camadas & $10-32 \mathrm{~mm}$ e 32 - 125 mm \\
\hline Carga Alto-Forno: & \\
(\% em volume) & $6-16 \mathrm{~mm}$ \\
Minério Granulado HTT 5\% & $8-18 \mathrm{~mm}$ \\
Pelota A 4\% & $8-18 \mathrm{~mm}$ \\
Pelota B 14\% & $15-23 \mathrm{~mm}$ \\
Fundentes 2\% & $32-125 \mathrm{~mm}$ \\
Carvão Grosso 39\% & $10-32 \mathrm{~mm}$ \\
Carvão Médio 36\%
\end{tabular}

Conhecendo-se: as vazões experimentadas, a altura da camada do leito granulado e as condições de temperatura e pressão da experiência, ficam então definidos as variáveis os valores de $\Delta \mathrm{P}, \mathrm{H}, \mathrm{V}_{0}, \mu_{\mathrm{g}}$, e $\rho_{\mathrm{g}}$ na equação de Ergun (2), restando apenas as variáveis que estão relacionadas às características do leito $\left(\mathrm{k}_{1} \mathrm{e} \mathrm{k}_{2}\right)$. Essas variáveis são então obtidas através da linearização dos dados, obtendo uma equação da forma: $Y=A X+B$.

\section{RESULTADOS E DISCUSSÃO}

\subsection{Ensaios para a Determinação da Esfericidade, Fração de Vazios e Tamanho Médio}

Os carvões apresentam as maiores frações de vazio permitindo maior permeabilidade gasosa quando comparado aos outros materiais estudados, sendo o carvão grosso o de

* Contribuição técnica ao 44 Seminário de Redução de Minério de Ferro e Matérias-primas, 15ำ Simpósio Brasileiro de Minério de Ferro e $2^{\circ}$ Simpósio Brasileiro de Aglomeração de Minério de Ferro, 15 a 18 de setembro de 2014, Belo Horizonte, MG, Brasil. 


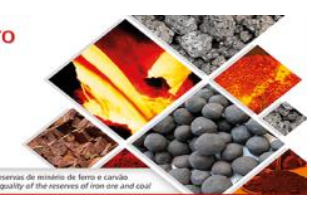

maior fração de vazios. A HTT possui a menor fração de vazio devido ao seu formato e grau de acomodação entre suas partículas.

No que diz respeito as pelotas, a esfericidade ficou próximas de 1 . Os 2 tipos de pelota estudadas (Fornecedor $\mathrm{A}$ e $\mathrm{B}$ ) apresentaram diferenças em relação à distribuição de tamanho. Enquanto apenas $14,7 \%$ da Pelota $A$ encontra-se retida na malha de $12,7 \mathrm{~mm}$, na Pelota B esse percentual sobe para $55,1 \%$. Devido a isso a Pelota B possui maior tamanho médio se comparada com a Pelota $\mathrm{A}$.

Tabela 2: Resultados de $\mathrm{k}_{1}$ e $\mathrm{k}_{2}$ obtidos a partir das medições de Esfericidade, Fração de Vazios e Tamanho Médio

\begin{tabular}{cccccc} 
Material & $\varphi$ & $\varepsilon$ & $\begin{array}{c}\mathrm{d} \\
(\mathrm{m})\end{array}$ & $\begin{array}{c}\mathrm{k}_{1} \\
\left(\mathrm{~m}^{-2}\right)\end{array}$ & $\begin{array}{c}\mathrm{k}_{2} \\
\left(\mathrm{~m}^{-1}\right)\end{array}$ \\
\hline Pelota A (8-18mm) & 0,98 & 0,25 & 0,011 & $4,77 \mathrm{E}+07$ & 7.800 \\
\hline Pelota B (8-18mm) & 0,96 & 0,22 & 0,012 & $5,87 \mathrm{E}+07$ & 10.495 \\
\hline NPO (6-30mm) & 0,47 & 0,29 & 0,021 & $3,17 \mathrm{E}+07$ & 5.246 \\
\hline HTT (6-16mm) & 0,43 & 0,20 & 0,010 & $6,63 \mathrm{E}+08$ & 41.132 \\
\hline Carvão Médio (32-10mm) & 0,39 & 0,28 & 0,018 & $6,60 \mathrm{E}+07$ & 7.677 \\
\hline Carvão Grosso (125-32mm) & 0,34 & 0,33 & 0,037 & $1,24 \mathrm{E}+07$ & 2.676 \\
\hline Carvão (10-125mm) & 0,37 & 0,26 & 0,027 & $4,94 \mathrm{E}+07$ & 7.798 \\
\hline
\end{tabular}

\subsection{Ensaios de Permeabilidade}

A Figura 2 apresenta os resultados obtidos nos ensaios de permeabilidade.

* Contribuição técnica ao 44 Seminário de Redução de Minério de Ferro e Matérias-primas, 15ํㅡㄴ Simpósio Brasileiro de Minério de Ferro e $2^{\circ}$ Simpósio Brasileiro de Aglomeração de Minério de Ferro, 15 a 18 de setembro de 2014, Belo Horizonte, MG, Brasil. 

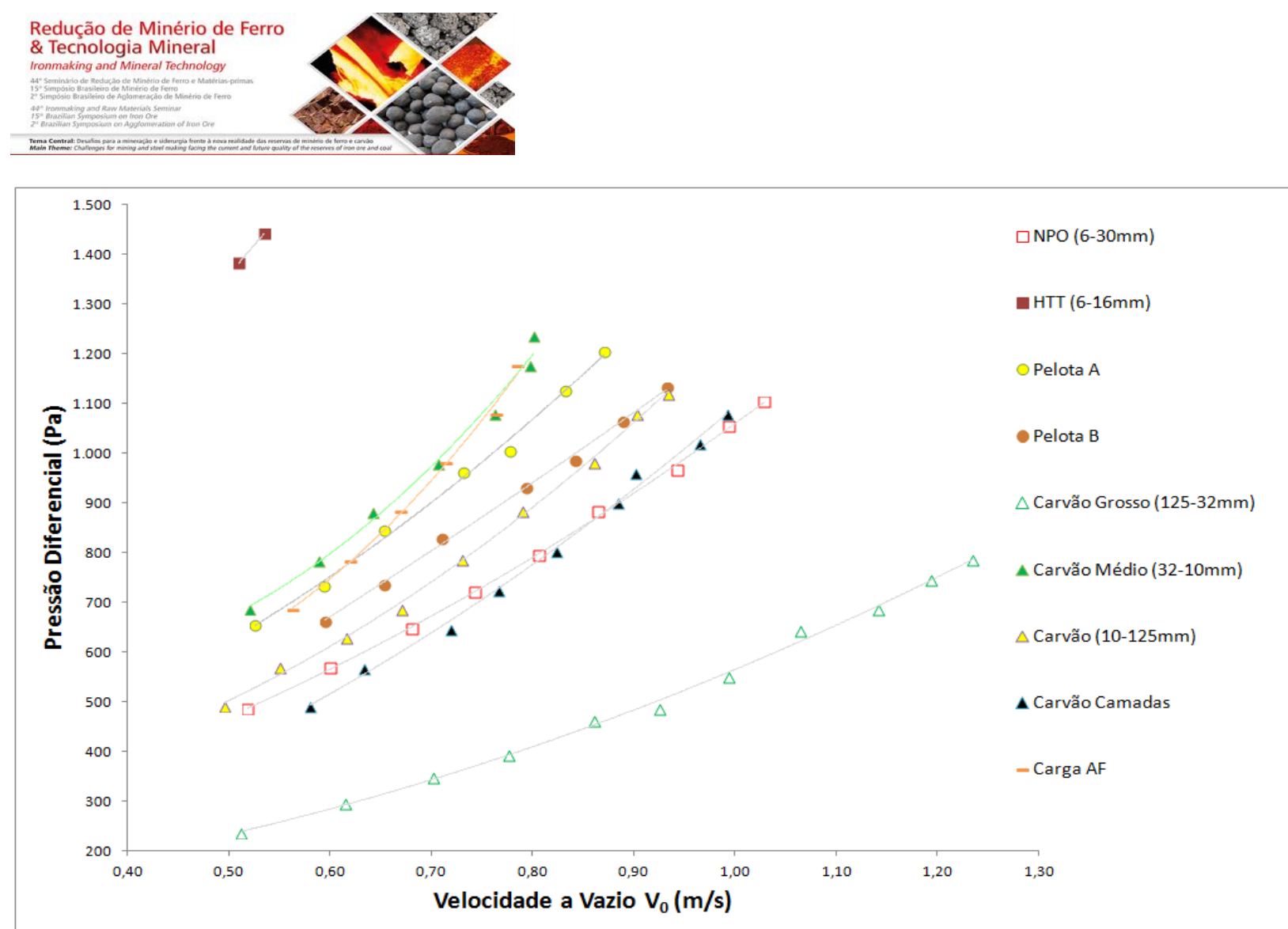

Figura 2: Variação da queda de pressão com a velocidade a vazio obtidos nos ensaios de permeabilidade.

Considerando os resultados do carvão vegetal, é possível perceber a perda de carga significativa quando há alteração do tipo de carvão estudado. Como já era esperado, o carvão capaz de oferecer a menor resistência à passagem do gás é o carvão grosso e a maior resistência a este mesmo gás, é o carvão médio. O carvão que cobre toda a faixa granulométrica $(10-125 \mathrm{~mm})$ apresentou resistência intermediária. Ou seja, mesmo o estreitamento da faixa granulométrica do carvão médio não foi capaz de compensar a redução do tamanho médio. Adicionalmente, o carvão médio e grosso quando são dispostos em camadas no leito granulado oferecem menor perda de carga, exceto para o carvão grosso que, devido ao seu elevado tamanho médio, permanece como sendo o material mais permeável, dentro os estudados.

No que diz respeito às cargas metálicas, a hematitinha apresentou valores de perda de carga bem superiores aos demais e devido à limitação da perda de carga do ventilador, somente foi possível obter 2 pontos no gráfico, não sendo portanto razoável a geração dos resultados de linearização da relação de perda de carga e velocidade do gás a vazio.

Apesar dos resultados estarem relativamente próximos, veja que a permeabilidade do minério NPO ficou superior aos resultados da pelota de ambos os fornecedores, mais uma vez, graças ao maior tamanho médio.

Também foi avaliada a perda de carga de um leito formado com materiais normalmente empregados na fabricação do ferro-gusa. Os resultados ficaram em patamares

* Contribuição técnica ao 44 Seminário de Redução de Minério de Ferro e Matérias-primas, 15은 Simpósio Brasileiro de Minério de Ferro e $2^{\circ}$ Simpósio Brasileiro de Aglomeração de Minério de Ferro, 15 a 18 de setembro de 2014, Belo Horizonte, MG, Brasil. 


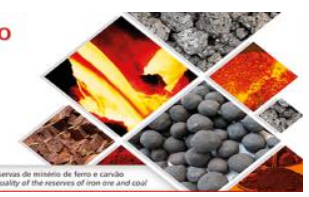

superiores a todos os materiais estudados para toda a faixa de velocidade, exceto para a hematitinha, lembrando que esta compõe $20 \%$ da carga metálica estudada.

No que se refere a avaliação do efeito na perda de carga quando há peneiramento da pelota e portanto remoção dos finos nela contido, que no caso do experimento era de $2 \%$, o resultado do ensaio de permeabilidade evidencia que a diferença não foi significativa. Ou seja, a remoção de $2 \%$ dos finos na pelota não gera efeito significativo, no que diz respeito apenas ao escoamento gasoso.

Em todos os casos estudados, quanto maior a velocidade a vazio, maior o diferencial de pressão. Além disso, a diferença dos resultados de diferencial de pressão entre os experimentos é maior quanto maior é a velocidade a vazio. Ou seja, quanto maior for a velocidade a vazio, maior deverá ser o cuidado necessário com a qualidade da carga enfornada no alto-forno considerando apenas a permeabilidade.

De posse dos valores de Pressão $x$ Velocidade a vazio, obtidos nos ensaios de permeabilidade, foi calculado os valores de $k_{1}$ e $k_{2}$ novamente (Tabela 3).

Tabela 3: Resultados de $\mathrm{k}_{1}$ e $\mathrm{k}_{2}$ obtidos a partir dos ensaios de permeabilidade

\begin{tabular}{ccc} 
Material & $\begin{array}{c}\mathrm{k}_{1} \\
\left(\mathrm{~m}^{-2}\right)\end{array}$ & $\begin{array}{c}\mathrm{k}_{2} \\
\left(\mathrm{~m}^{-1}\right)\end{array}$ \\
\hline Pelota A (8-18mm) & $5,48 \mathrm{E}+07$ & 380 \\
\hline Pelota B (8-18mm) & $5,10 \mathrm{E}+07$ & 268 \\
\hline NPO (6-30mm) & $4,17 \mathrm{E}+07$ & 265 \\
\hline HTT (6-16mm) & - & - \\
\hline Carvão Médio (32-10mm) & $5,08 \mathrm{E}+07$ & 640 \\
\hline Carvão Grosso (125-32mm) & $1,72 \mathrm{E}+07$ & 238 \\
\hline Carvão (10-125mm) & $3,95 \mathrm{E}+07$ & 462 \\
\hline
\end{tabular}

Comparando os valores dos coeficientes da equação de Ergun ( $k_{1}$ e $\left.k_{2}\right)$ obtidos nas Tabelas 2 e 3, percebe-se uma diferença de 13 a 30\% entre os valores de $k_{1}$ para uma mesma amostra. Entretanto, para os valores de $k_{2}$, os valores são bem discrepantes. Embora os valores de $\mathrm{k}_{1}$ sejam mais significativos para o cálculo da perda de carga em um leito granulado, o método de determinação dos coeficientes de Ergun pela determinação das características geométricas do leito: fração de vazio, esfericidade e tamanho médio, não demonstrou ser confiável.

\subsection{Determinação da Velocidade de Fluidização e Diâmetro de Corte}

A Figura 3 no qual estão plotados não só os valores encontrados nesta pesquisa mais também os valores referência de velocidade de fluidização obtidos por Silveira em 1973, nos mostra a velocidade de fluidização em dependência com o diâmetro médio do carvão vegetal e do coque. Os valores de $V_{f}$ foram obtidos da equação [5], sendo que a viscosidade e a densidade do gás do alto-forno foram calculadas para uma temperatura de $250^{\circ} \mathrm{C}$. Pode-se verificar que para um mesmo diâmetro médio, a velocidade de fluidização $V_{f}$ para o coque é bem superior aquela do carvão vegetal.

* Contribuição técnica ao 44 Seminário de Redução de Minério de Ferro e Matérias-primas, 15ํㅡㄴ Simpósio Brasileiro de Minério de Ferro e $2^{\circ}$ Simpósio Brasileiro de Aglomeração de Minério de Ferro, 15 a 18 de setembro de 2014, Belo Horizonte, MG, Brasil. 


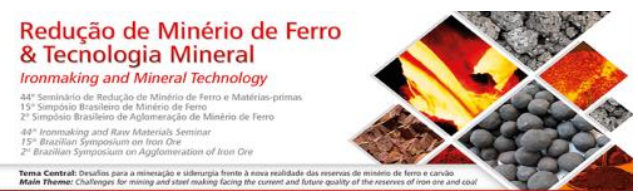

Assim, para um alto-forno cujo diâmetro da goela é $4,2 \mathrm{~m}$ e cuja produção de gás é $40.000 \mathrm{Nm}^{3} / \mathrm{hr}$, seriam fluidizadas: as partículas de coque inferiores a $3 \mathrm{~mm}$; as partículas de carvão vegetal inferiores a $5,8 \mathrm{~mm}$; e as de carvão vegetal de origem plantada (objeto deste estudo) inferiores a $9,5 \mathrm{~mm}$. Convém chamar a atenção para o fato de que este estudo é feito para uma distribuição regular da correte gasosa. Entretanto, se isto não ocorrer, maiores velocidades poderiam suceder-se, provocando fluidização de partículas com diâmetros superiores aos acima citados.

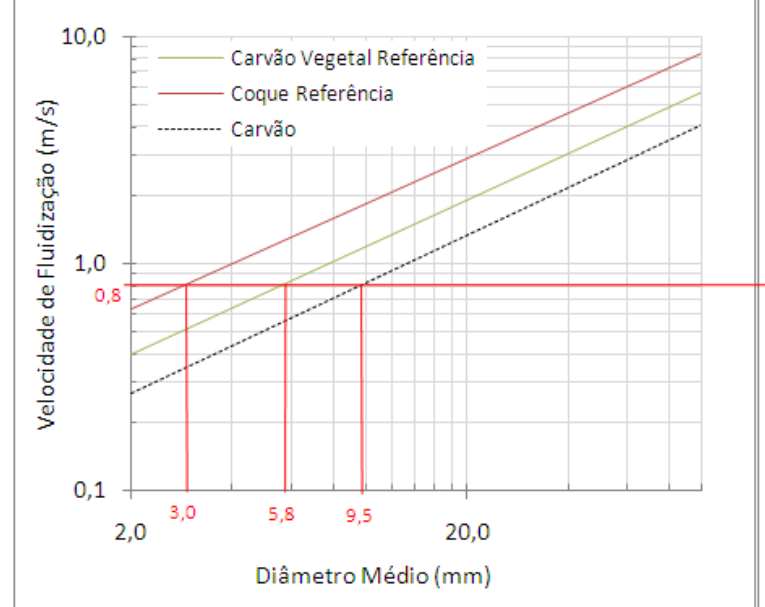

a) Velocidade de fluidização em dependência com o diâmetro médio do carvão vegetal e do coque

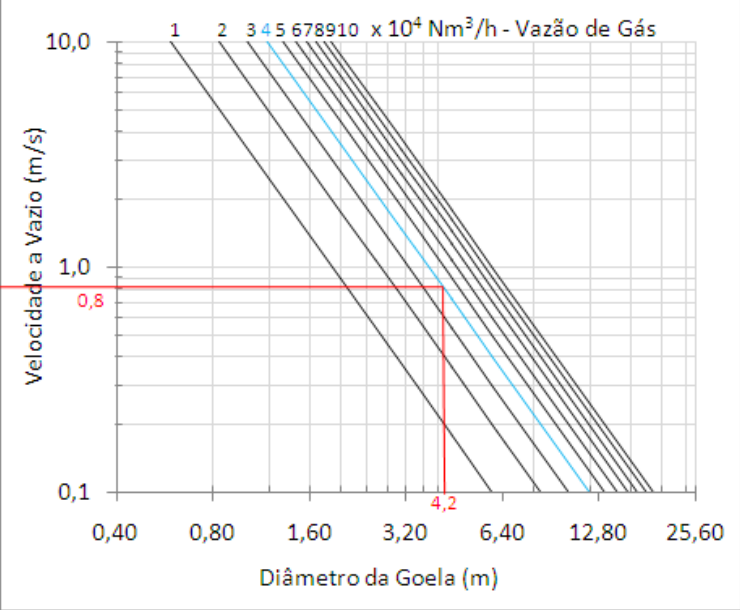

b) Velocidade a vazio em dependência com o diâmetro da goela para diversas vazões do gás

Figura 3: Determinação do diâmetro crítico do carvão vegetal e do coque quando se conhecem o diâmetro da goela e a vazão de gás em um dado alto-forno.

\section{CONCLUSÕES}

Quando maior for a vazão de gás aplicada em um dado alto-forno, e portanto maior a velocidade a vazio maior será o diferencial de pressão sofrido pelo gás ao percorrer a camada de leito poroso. Com relação aos minérios, o minério de ferro HTT produz efeito de diferencial de pressão 3 vezes maior que o minério de ferro NPO devido ao seu pequeno tamanho médio e elevado percentual de material abaixo de $6,35 \mathrm{~mm}$. Já a pelota oferece a menor resistência a passagem do gás e portanto possui os menores valores de diferencial de pressão, no que diz respeito a carga metálica.

Em relação ao carvão vegetal, o tamanho médio demonstrou grande influência na permeabilidade dos leitos. O aumento de tamanho médio do carvão de 21 para $79 \mathrm{~mm}$ provoca redução de diferencial de pressão para 1/3. A redução do diferencial de pressão do gás com a distribuição do carvão em camadas é maior com velocidades a vazio do gás maiores que $0,65 \mathrm{~m} / \mathrm{s}$.

Os ensaios de permeabilidade demonstraram ser o método mais indicado para a determinação dos coeficientes da Equação de Ergun, devido principalmente às diferenças significativas encontradas nos valores de $\mathrm{k}_{2}$.

* Contribuição técnica ao 44 Seminário de Redução de Minério de Ferro e Matérias-primas, 15ำ Simpósio Brasileiro de Minério de Ferro e $2^{\circ}$ Simpósio Brasileiro de Aglomeração de Minério de Ferro, 15 a 18 de setembro de 2014, Belo Horizonte, MG, Brasil. 


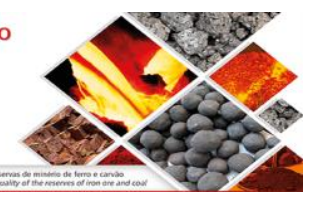

Utilizando as curvas da velocidade de fluidização determinadas experimentalmente torna-se possível determinar o diâmetro crítico das partículas de carvão para um dado alto-forno e é possível determinar o nível máximo de produção para um dado alto-forno e diâmetro médio das partículas de carvão vegetal.

\section{Agradecimentos}

Os autores agradecem ao CAPES-PROEX, CNPq e FAPEMIG que colaboraram na execução desta pesquisa e pelo auxílio técnico proporcionado. Os autores também agradecem a Vallourec Tubos do Brasil S.A. pela autorização concedida para publicação deste trabalho.

\section{BIBLIOGRAFIA}

1 Ergun S. "Fluid Flow through Packed Columns", Chemical Engineering Progress, vol. 48, American Institute of Chemical Engineers: New York, 1952, pp. 89-94.

2 Jeschar R, Potke WP, Polthier L. Blast Furnace aerodynamics, Wollongong, Austrália, 1975, p. 136-147.

3 Silveira RC, Melo MAL. Contribuição ao Escoamento Gasoso no alto-forno, Contribuição técnica apresentada no XXVIII Congresso Anual da ABM, Salvador, Ba, 1973.

4 Standish N, Borger DE. In: Blast furnace aerodynamics, Hamilton, Canadá, 1987, p. 3.1-3.7.

5 Standish J. \& Willians. The structure and flow resistence of the coke-ore interface. In: Blast Furnace Aerodynamics, Wollongong, Austrália, 1975, p. 9.

6 Szekely J, Propster M. The structure and flow resistance of layer charged particulate systems in the modeling of gas flow through simulated blast furnace burdens. Trans. ISIJ, 1979; 19: 11-20.

7 Szekely J, Propster M. Theoretical prediction of non-uniform gas flow through simulated blast furnace burdens. Trans. ISIJ, 1979; 19: 21-30.

8 Tambasco MJA. Redução de Minério de Ferro em Alto-Forno, São Paulo, ABM, $3^{a}$ ed., Cap. II, 1976, p. 77-198.

9 Figueira RM, Tavares RP. Desenvolvimento da Tecnologia do Alto-Forno, Belo Horizonte, UFMG, Cap. 7, Parte I, 1984, p. 433-484.

* Contribuição técnica ao 44 Seminário de Redução de Minério de Ferro e Matérias-primas, 15ำ Simpósio Brasileiro de Minério de Ferro e $2^{\circ}$ Simpósio Brasileiro de Aglomeração de Minério de Ferro, 15 a 18 de setembro de 2014, Belo Horizonte, MG, Brasil. 